\title{
An update: Prevalence of rabies in animalsbetween 2010 and 2017in north-eastern Romania
}

\author{
Mihaela-Anca DASCALU*, Florentina BOCANETI, Oana TANASE, Elena VELESCU \\ Department of Public Health, Faculty of Veterinary Medicine, University of Agricultural Sciences and \\ Veterinary Medicine „Ion Ionescu de la Brad",Iasi, Romania \\ *corresponding author: dascalu_ancamihaela@yahoo.com
}

Bulletin UASVM Veterinary Medicine 75(2)/2018

Print ISSN 1843-5270; Electronic ISSN 1843-5378

doi:10.15835/buasvmcn-vm: 2018.0042

\begin{abstract}
:
In order to obtain an overview of the situation of rabies positive cases, but also to establish a true prevalence of the disease among domestic and wild animals, an epidemiological survey was conducted in the north east of the country, targeting the 8 counties of Moldova region,over a period of eight years, between 2010 and 2017. A total of 2306 brain samples coming from animals with suspicion of rabies were received at the laboratories, from which $851(36,90 \%)$ were represented by domestic animals and $1455(63,10 \%)$ by wild animals. Following the implementation of the referenced techniques in rabies diagnosis, out of 2306tested samples, $492(21,36 \%)$ were confirmed positive and 1814 negative $(78,66 \%)$.

Out of 1455 samples coming from wild animals, 303 (20,82\%) were confirmed positive, with a total prevalence of $21,32 \%$, while in the case of domestic animals out of 851 samples, 189 were positive, with a total prevalence of $22,20 \%$.
\end{abstract}

Keywords: epidemiology, rabies, Romania

\section{Introduction}

Centuries old, rabies remainsone of the most severeand lethal zoonosis that affects all homeothermicanimals and humans, being produced by a virus belonging to the Rhabdoviridae Family, Lyssavirus Genus (ICTV, 2017).

During the last decades, rabies has been eradicated from the west and center Europe by using intensive programs which consisted in the distribution of vaccine baits targeting wild foxes and mass vaccinations of pets (Brochier et al., 1995; Bugnon et al., 2004; Matouch et al., 2007), considered to be the only effective methods to eradicate the disease and brake the infectious cycle between animals and people.

The aim of the study was to obtain an overview of the situation of rabies positive cases, but also to establish a true prevalence of the disease among domestic and wild animals. In this respect, an epidemiological survey was conductedin the north east of the country, targeting the 8 counties of Moldova region, over a period of eight years, between 2010 and 2017.

\section{Materials and methods}

For better understandthe distribution of positive rabies cases, data have been collected since 2010, prior to the implementation of the strategic program regarding the oral vaccination of foxes, first applied in our country in 2011. Thus, these data were obtained from eachof the Sanitary Veterinary and Food Safety Directionand correlated with the official statementsreported by the OIE. The counties included in the study were represented by Suceava, Botosani, Iasi, Piatra Neamt, Bacau, Vaslui, Galati and Vrancea (Figure $1)$. 


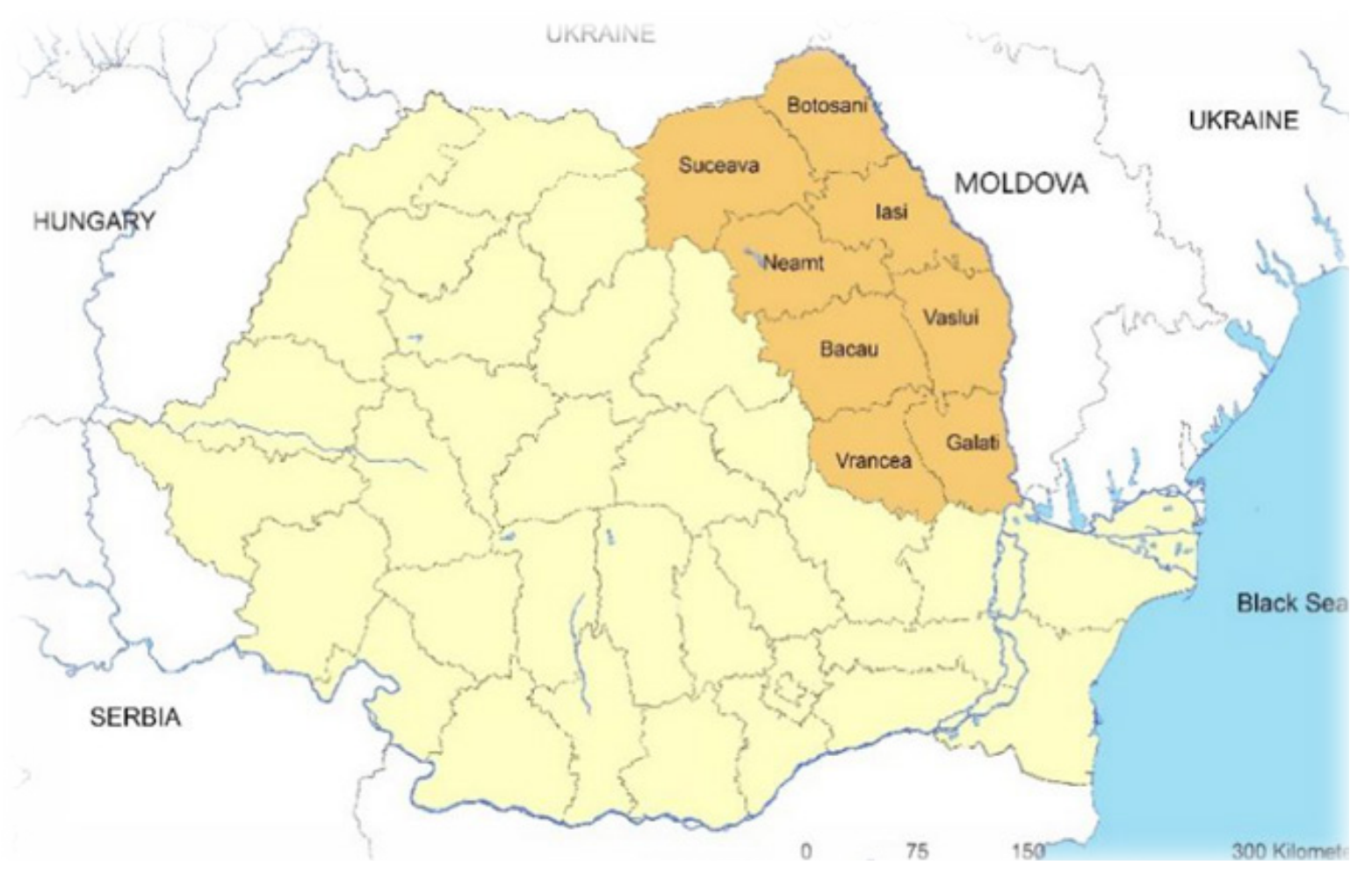

Figure 1. Map of Romania with geographical origin of the 8 counties studied (original)

Between 2010 and 2017, a total of 2306 brain samples coming from animals with suspicion of rabies were received at the laboratories, from which 851 (36.90\%) were represented by domestic animals and 1455 (63.10\%) by wild animals. Out of 2306 samples, 153 came from Vrancea county, 87 from Galati county, 238 from Bacau county, 207 from Vaslui county, 130 from Piatra Neamt county, 632 from Iasi county, 625 from Suceava county and 234 from Botosani county.

Regarding domestic animals, most of the samples came from dogs $(\mathrm{No}=335), 243$ from cattles, 172 from cats, 42 from sheeps, 33 from goats, 11 from horses, 9 from rabbits and 6 from pigs. In a higher proportion (63.10\%), as expected, the samples were coming from wild animals,especially from the sylvatic reservoir of rabies, represented by the fox,with a total of 1391 brain samples.In a lower proportion,other 64 brain samples coming from other wild animals were received at the laboratory: ferrets $(\mathrm{No}=14)$, wild cats $(\mathrm{No}=10)$, wolfs $(\mathrm{No}=9)$, roebucks $(\mathrm{No}=8)$, martens $(\mathrm{No}=5)$, badgers $(\mathrm{No}=5)$, deer's $(\mathrm{No}=5)$, weasel $(\mathrm{No}=1)$, squirrel $(\mathrm{No}=1)$, lama $(\mathrm{No}=1)$, hamster $(\mathrm{No}=1)$, otter $(\mathrm{No}=1)$, lynx $(\mathrm{No}=1)$, rat $(\mathrm{No}=1)$ and wild boar $(\mathrm{No}=1)$.

All the samples were tested using the referenced techniques in rabies diagnosis, recommended by both WHO and OIE, namely Direct Fluorescent Antibody Test and Mouse Inoculation Test, as described in OIE, Terrestrial Manual, 2018.

\section{Results and discussions}

Following the implementation of the referenced techniques in rabies diagnosis in the related laboratories, out of 2306tested samples coming from both domestic and wild animals during the study period, 492 samples $(21,36 \%)$ were confirmed positive and 1814 negative $(78,66 \%)$.

Situation of rabies cases in domestic animals. As concerning domestic animals, 189 positive samples out of 851 were diagnosed, from which 104 (55.03\%) were reported in cattle, 47 (24.87\%) in dogs, $25(13.23 \%)$ in cats, $6(3.17 \%)$ in sheep's, 3 in horses $(1.59 \%), 3$ in goats $(1.59 \%)$ and one $(0.52 \%)$ in pigs, resulting a prevalence of $22.20 \%$ (Figure 2). 


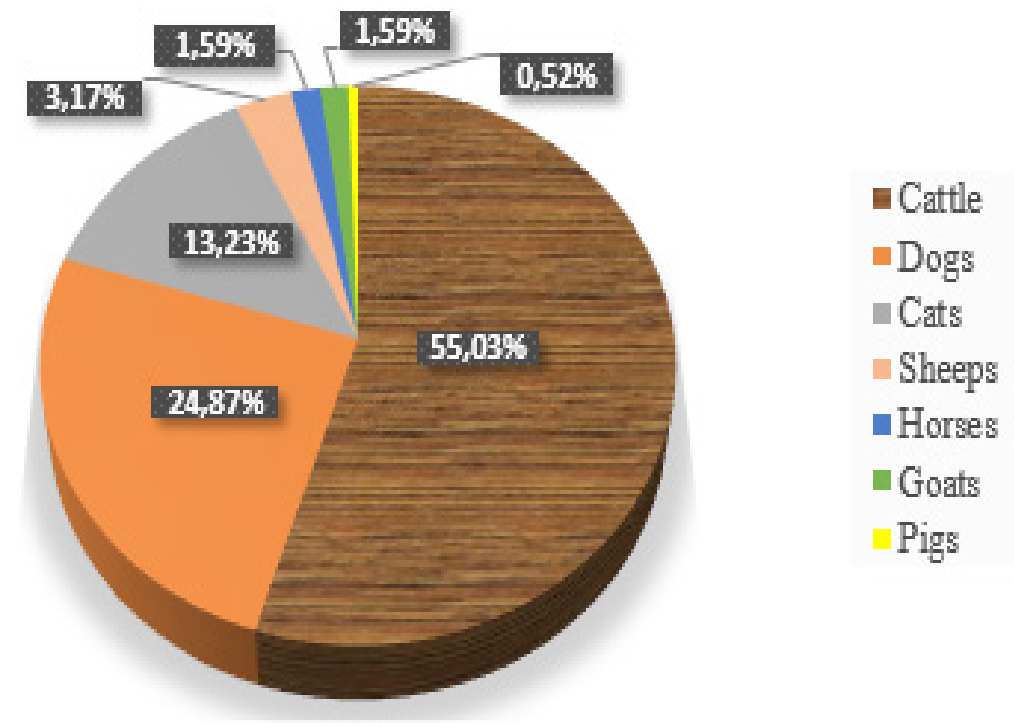

Figure 2. The positive cases of rabies recorded in domestic animals during 2010-2017 in Moldova counties

Table 1.The total number of samples tested during 2010-2017 and the results obtained at the confirmation diagnosis for the 8 counties studied

\begin{tabular}{|c|c|c|c|c|c|c|c|c|c|c|c|c|c|c|c|c|c|c|}
\hline \multirow{2}{*}{ Species } & \multicolumn{2}{|c|}{ BT } & \multicolumn{2}{|c|}{ SV } & \multicolumn{2}{|c|}{ IS } & \multicolumn{2}{|c|}{ NT } & \multicolumn{2}{|c|}{ VS } & \multicolumn{2}{|c|}{ BC } & \multicolumn{2}{|c|}{ GL } & \multicolumn{2}{|c|}{ VN } & \multicolumn{2}{|c|}{ Total } \\
\hline & + & - & + & - & + & - & + & - & + & - & + & - & + & - & + & - & + & - \\
\hline Cow & 19 & 17 & 38 & 20 & 20 & 16 & 8 & 21 & 8 & 31 & 7 & 21 & 4 & 0 & 0 & 13 & 104 & 139 \\
\hline Dog & 7 & 22 & 4 & 37 & 14 & 81 & 4 & 25 & 5 & 30 & 2 & 49 & 8 & 13 & 3 & 31 & 47 & 288 \\
\hline Cat & 1 & 1 & 1 & 15 & 11 & 64 & 0 & 6 & 6 & 11 & 3 & 23 & 1 & 17 & 2 & 10 & 25 & 147 \\
\hline Sheep & 0 & 3 & 2 & 5 & 0 & 7 & 0 & 9 & 4 & 4 & 0 & 7 & 0 & 0 & 0 & 1 & 6 & 36 \\
\hline Horse & 0 & 1 & 0 & 2 & 3 & 1 & 0 & 0 & 0 & 1 & 0 & 0 & 0 & 1 & 0 & 2 & 3 & 8 \\
\hline Goat & 0 & 1 & 2 & 1 & 0 & 1 & 0 & 5 & 0 & 3 & 0 & 9 & 1 & 0 & 0 & 10 & 3 & 30 \\
\hline Pig & 0 & 0 & 0 & 1 & 1 & 1 & 0 & 0 & 0 & 2 & 0 & 1 & 0 & 0 & 0 & 0 & 1 & 5 \\
\hline Rabbit & 0 & 0 & 0 & 0 & 0 & 0 & 0 & 8 & 0 & 0 & 0 & 1 & 0 & 0 & 0 & 0 & 0 & 9 \\
\hline Total & 27 & 45 & 47 & 81 & 49 & 171 & 12 & 74 & 23 & 82 & 12 & 111 & 14 & 31 & 5 & 67 & 189 & 662 \\
\hline
\end{tabular}

Most cases of rabies in cattleconfirmed during these years were recorded in Suceava county with a total of 38 cases, followed by Iasi with 20 cases, Botosani with 19 cases,Neamt and Vaslui counties with 8 cases each, Galati county with 4 cases and zero cases for Vrancea county.

The second most affected species was represented by the dogs with a total of 47 cases. Most of those were confirmed in Iasi with 11 cases, followed by Galati with 8 cases, 7 cases in Botosani, 5 cases in Vaslui, 4 cases in Suceava and Neamt respectively, at the opposite side being the counties of Vrancea and Vaslui with 3 and 2 cases, respectively.
Also, one of the species most affected were the cats with 25 cases, 11 of them being reported in Iasi county, 6 in Vaslui, 3 in Bacau and 2 in Vrancea. In Botosani, Suceava and Galati counties only 1 case per each were reported.

Of those least affected species were the sheeps. Only 6 positive cases were reported, of which 4 in Vaslui and 2 in Suceava. Few cases were reported also in horses with a total of 3 cases, all diagnosed in Iasi county. In goats, 3 cases were confirmed, 2 in Suceava and one in Galati and one case in a pig in Iasi county.

The most affected counties by rabies among domestic animals were represented by Iasi and 


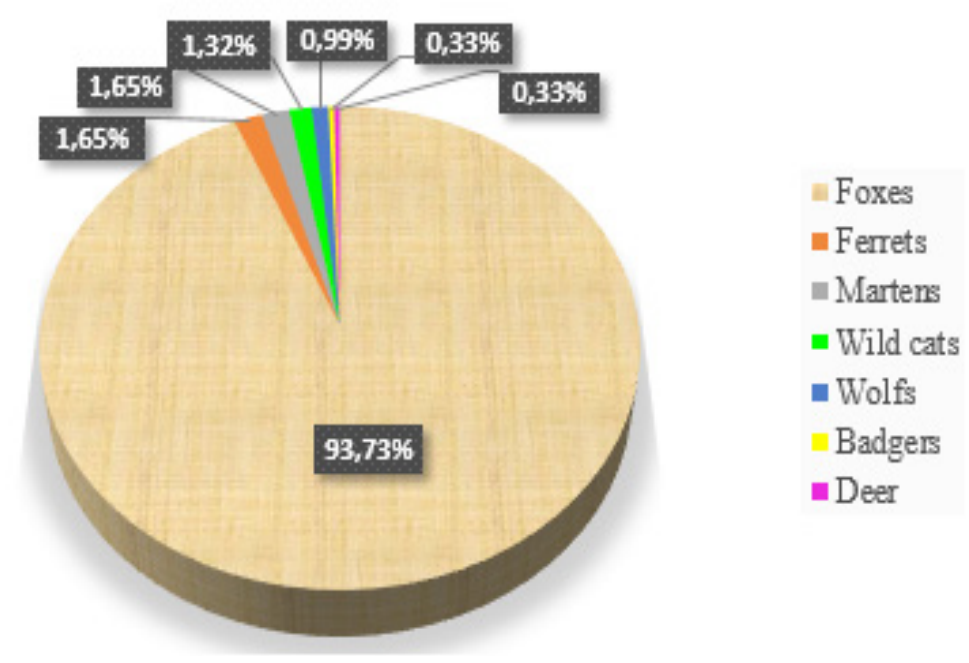

Figure 3. The positive cases of rabies recorded in wild animals during 2010-2017 in Moldova counties

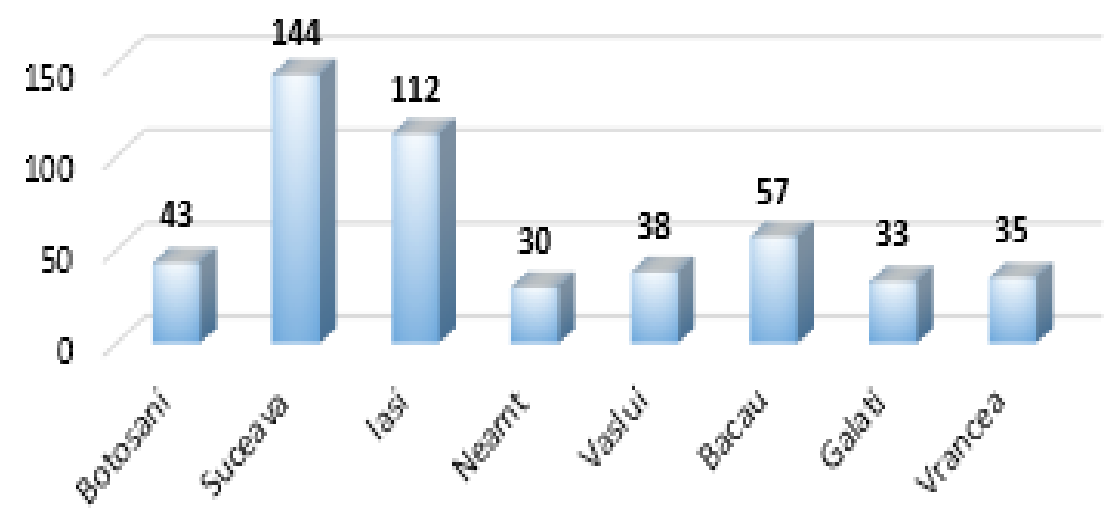

Figure 4. Total number of positive rabies cases recorded in Moldova counties between 2010-2017

Suceava with 49 respectively 47 cases, followed by Botosani with 27 cases, Vaslui with 23 cases, and at the opposite pole, Galati with 14 cases, Bacau and Neamt with 12 cases each and 5 cases for Vrancea (Table 1).

Situation of rabies cases in wild animals Regarding the wild animals, 303 positive samples out of 1455 were found, with the highest percentage of positive cases in foxes. Thus, 284 positive cases $(93.73 \%)$ were reported in foxes, $5(1.65 \%)$ in martens, $5(1.65 \%)$ in ferrets, $4(1.32 \%)$ in wild cats, $3(0.99 \%)$ in wolves and one case in badger $(0.33 \%)$, respectively in roebuck $(0.33 \%)$, with a total prevalence of $21.32 \%$ (Figure 3 ).

As concerning the positive cases in foxes, most of them were reported in Suceava and Iasi county with 93 , respectively 60 cases, followed by Bacau county with 40 cases and Vrancea county with 25 cases. The fewest cases in foxes were registered in Neamt and Galati counties with 18 cases each, followed by Botosani and Vaslui counties with 15 cases each.

Five positive cases were registered also in martens, from which 3 in Suceava and 2 in Bacau counties and another 5 cases in ferrets, 3 of them in Iasi and 2 in Vrancea counties.

The wild cats were also affected by rabies, with a total of 4 cases reported in Vrancea, Galati, Bacau and Neamt counties. Rabies were also confirmed in wolfs, were 3 cases were diagnosed in Vrancea and Bacau counties. The least affected were the badger and the roebuck with one case confirmed in Suceava, respectively in Bacau counties. 
To summarize, of all the positive cases recorded in both domestic and wild animals, the main affected county was Suceava with 144 cases, followed by Iasi with 112 cases, Bacau with 57 cases, Botosani with 43 cases, Vaslui with 38 cases, at the opposite pole being the counties of Vrancea, Galati and Neamt with 35, 33 and 30 cases, respectively (Figure 4).

Since 2011, our country dispose of a national program regarding the surveillance, control and eradication of rabies in foxes, approved for a period of 10 years, a program that involves a biannual distribution of the baits in the habitat of these animals (Government Decision No. 55/2008). Although Romania has been one of the most affected rabies countries at European level over the past decades (Rabies Bulletin Europe, 2018; WAHIS, 2018), with the implementation of this program, the number of positive cases of rabies among animals have declined significantly.

\section{Conclusions}

Out of 1455 wild animals samples received at the related laboratory during the 8 years study, $303(20.82 \%)$ were confirmed positive, with a total prevalence of $21.32 \%$. As expected, the foxes were the most affected species with 284 (93.73\%) cases. The highest number of rabies cases in wild animals were reported in Suceava county summing 93 cases.

Out of 851 domestic animals samplesreceived at the laboratory with rabies suspicion, 189 $(22.20 \%)$ were confirmed positive, with a total prevalence of $22.20 \%$.The cattles were the most affected domestic species with 103 cases, most of them being confirmed in Iasi county, area with a total of 48 cases.

The massive vaccination of the foxes and pets has led to the eradication of rabies in Western Europe over the last decades, being the only effective ways to eliminate the disease and break the infectious cycle between animals and humans.

Acknowledgments. This research did not receive any specific grant from funding agencies in the public, commercial or not-for-profit sectors.

\section{References}

1. Brochier B, Costy F, Pastoret PP (1995).Elimination of fox rabies from Belgium using a recombinant vaccinia-rabies vaccine: an update. Vet Microbiol., 46(1-3):269-79.

2. Bugnon P, Breitenmoser U, Peterhans E, Zanoni R(2004). Efficacy of oral vaccination in the final stage of fox rabies elimination in Switzerland. J Vet Med B Infect Dis Vet Public Health., 51(10):433-7.

3. Government Decision No. 55/2008 for the approval of Strategic Plan for the surveillance, control and eradication of rabies in foxes in Romania.

4. ICTV (2017).Virus Taxonomy: The Classification and Nomenclature of Viruses. The Online $\left(10^{\text {th }}\right)$ Report of the International Committee on Taxonomy of Viruses. https://talk.ictvonline.org/ictv-reports/ictv_online_ report/ Accessed 02.08.2018.

5. Matouch O, Vitasek J, Semerad Z, Malena M (2007). Rabies-free status of the Czech Republic after 15 years of oral vaccination. Rev Sci Tech., 26(3):577-84.

6. OIE (2018). Terrestrial Manual, Chapter 2.1.17 Rabies (Infection with rabies virus and other Lyssaviruses), ed. OIE, Paris.

7. Rabies - Bulletin - Europe (2018). Rabies Information System of the WHO.https://www.who-rabies-bulletin. org/ Accessed 03.08.2018.

8. WAHIS - Wild Interface (2018). http://www.oie.int/ wahis_2/public/wahidwild.phpAccessed 03.08.2018. 